\title{
ALGUMAS REFLEXÕES SOBRE A ÉTICA DESPORTIVA
}

\author{
SOME CONSIDERATIONS \\ ABOUT SPORT ETHICS
}

\author{
AUTORES \\ Carla Marisa Moreira ${ }^{1}$ \\ Gui Duarte Pestana \\ ${ }^{1}$ Escola EB 2,3 D. Afonso Henriques \\ ${ }^{2}$ Escola EB 2,3 Maria Lamas
}

\section{ALGUMAS REFLEXÕES SOBRE A ÉTICA DESPORTIVA 4(3): 95-101}

\section{PALAVRAS-CHAVE}

ética; desporto; fair-play; jovens; valores.

\section{KEYWORDS}

ethics; sport; fair play; adolescents; values.
RESUMO

Numa sociedade em que os valores estão em constantes alterações no comportamento de cada indivíduo, a identificação desses mesmos valores nos jovens atletas é de vital importância para melhor se entender o processo pelo qual eles tomam determinadas decisões, em situações desportivas.

As questões associadas à ética no desporto, e mais especificamente as que dizem respeito ao espírito desportivo e à tolerância, assumem hoje uma importância acrescida. De facto, não podemos negar a importância, nos diversos âmbitos, da prática e do espectáculo desportivo, mas há que reconhecer também que eles se revelam como campos especiais, nos quais os fins - ganhar - justificam quaisquer meios - violência, a corrupção, a fraude, o querer ganhar a todo e qualquer custo, o doping, a deslealdade, a ausência de espírito desportivo, etc.

A Ética Desportiva surge como uma estrutura moral que define alguns limites para o comportamento dos desportistas, de forma a preservar um sistema desportivo civilizado. É possivel competir respeitando o adversário, reconhecendo o seu valor e competência, vendo-o como um oponente indispensável, sem o qual não existe competição.

Vários investigadores defendem que a participação, das crianças e jovens, em actividades desportivas contribui para um desenvolvimento global e harmonioso das mesmas, pelo que se deverá dar atenção à importância do espírito desportivo como componente do processo de desenvolvimento da criança e jovem.

Com este trabalho pretendeu-se apresentar algumas reflexões sobre a aquisição de valores e princípios no contexto desportivo.
ABSTRACT

In a society in which the values are in constant alterations in the behaviour of each individual, identification of the same values in the young athletes is of vital importance in order that better the process is understood by which you link they take determined decisions, in athletic situations.

The questions associated to the ethics in the sport, and more specifically than concern the athletic spirit and the tolerance, assume today an added importance. In fact, we cannot deny the importance, in several extents, of the practice and of the athletic show, it is necessary to recognize them to me also what they reveal themselves how special fields, in which the ends to win - justify any ways - violence, the corruption, the fraud, to wanting to win to all and any cost, the doping, the disloyalty, the absence of athletic spirit, etc.

The Sports Ethics appears like a moral structure that defines some limits for the behaviour of the sportsmen, of form to preserve an athletic civilized system. It is possible to compete respecting the adversary, recognizing his value and competence, seeing it like an essential opponent, without whom there is not competition.

Several investigators defend that the participation, of the children and adolescents in physical activities contributes to a global and harmonious development of the same, because it will have to give attention to the importance of the athletic spirit like component of the process of development of the child and adolescents.

With this work some reflections were intended to present on the acquisition of values and beginnings in the athletic context. 


\section{INTRODUCÃO}

"Quando ganhar é tudo, fazemos tudo para ganhar"

(Nicholas, 1989)

O desporto é, de facto, um fenómeno cultural alvo de várias modificações. Este conceito sofre as alterações quase de modo instantâneo, na medida em que a sociedade evolui no redimensionamento dos seus princípios e dos seus valores".

Actualmente o desporto corre o sério risco de acumular um conjunto de perdas morais que o descredibilizam socialmente como factor educativo. 0 sistema desportivo não pode continuar a abrir mão de um conjunto de princípios e valores que assegurem sentido cultural e formativo à prática desportiva.

A aquisição de valores e princípios não se faz por imposição, por "decreto", pela simples leitura de documentos, é algo que se constrói, implicando, por isso, o seu "ensino" e a sua "prática". Esses princípios e valores têm de estar presentes em todas as dimensões e expressões da prática desportiva e são independentes do rendimento ou sucesso desportivos ${ }^{3}$.

O desporto faz parte da nossa sociedade, ambos são regidos pelos mesmos sistemas de normas e valores $^{4}$. Deste modo, e analisando a evolução do desporto moderno e dos valores sociais actuais, onde a ambição e os interesses pessoais subjacentes à competitividade dos estilos de vida adoptados se sobrepõem aos interesses sociais ${ }^{5}$, é legitimo questionar a aplicação da ética da mesma forma como foi entendida no passado.

Nesta perspectiva, o desporto, pelas suas regras, objectivos e exigências implica, na sua prática, o respeito por valores éticos e morais, tais como: solidariedade, honesti- dade, disciplina, paciência, compreensão, respeito pelo outro e pela regra, superação, trabalho, etc. ${ }^{6}$

É da responsabilidade pessoal e insubstituível que cada um - pais, professores, treinadores, dirigentes - tem em relação às crianças e jovens para as quais constitui um modelo de referência. Num ciclo de vida nacional em que os modelos de referência são constituídos e destruídos a uma velocidade vertiginosa, importa proporcionar aos jovens a oportunidade de conhecerem e conviverem com modelos positivos ${ }^{7}$.

0 acesso dos jovens à prática desportiva hoje em dia faz-se de forma generalizada, o problema consiste em fazer corresponder essa prática a princípios educativos e morais.

Deste modo surge a seguinte questão, sobre a qual vale a pena reflectir um pouco. Será que o modelo de Desporto de rendimento e as elevadas exigências, estará a proporcionar aos jovens, inferências e modelos correctos de prática desportiva? Assim, se é importante a divulgação e a defesa dos valores, princípios e mensagens éticas do Desporto, como contributo relevante para a moralização do acto desportivo, importa de igual modo denunciar todos aqueles que contribuem para a criação de situações lesivas e atentatórias daqueles princípios ${ }^{8}$. A validade positiva da função social que o desporto desempenha tanto no plano formativo como no educativo, obriga os vários responsáveis, ao adequado tratamento dos efeitos perversos consequentes da sobrevalorização dos aspectos negativos do seu universo, geradores de atitudes e comportamentos opostos às finalidades de um Desporto são e salutar. É por isto que a questão da ética e do fair-play no desporto não pode deixar de ser um imperativo. $^{9}$

\section{DESENVOLVIMENTO}

\section{1. Ética Desportiva e Fair Play}

Aristóteles conferiu a primeira versão sistemática da ética, definindo-a como sendo o compromisso efectivo do homem que o deve levar ao seu perfeccionismo pessoal, é o compromisso que se adquire consigo próprio de ser sempre mais pessoa. No sentido etimológico a palavra ética "compreende, antes de tudo, as disposições do homem na vida, o seu carácter, os seus costumes, e, naturalmente, também a sua moral" $^{10}$. Outro conceito pode ser atribuído à palavra ética, o qual no domínio da filosofia que tem por objectivo o juízo de apreciação que distingue o bem e o mal, o comportamento correcto e o incorrecto.

A ética é um ideal que tem sobressaído neste nosso mundo em constante mutação, considerando o homem como o novo valor absoluto dos tempos modernos e a moral como parte integrante do próprio ser humano ${ }^{11}$.

$O$ desporto é invadido pelos interesses da sociedade, cada vez mais sob a influência dos valores comerciais que muitas vezes o sustentam, vai ter, como tal, cada vez mais de respeitar as regras que norteiam aqueles interesses, mesmo que isso obrigue a algumas transformações da sua prática, em certos casos enraizada através de um passado de largos anos. Ora, esses interesses estarão, por certo, muito pouco preocupados com a ética desportiva.

Não é viável pensar somente em uma ética do desporto, pois uma ética desportiva, desvinculada de uma ética da sociedade, é impossível, uma vez que o desporto não se manifesta num vácuo social, mas acontece, sim, num contexto sócio-cultural, vinculado a uma ética da sociedade moderna ${ }^{12}$. 
A excessiva importância dada à vitória na prática desportiva, principalmente, a partir da profissionalização do desporto e os interesses económicos dos patrocinadores de atletas e eventos desportivos provocou profundas mudanças nas actividades desportivas, as quais passaram ferir os objectivos estabelecidos quando da criação do desporto moderno ${ }^{13} .0$ doping, a violência, as injurias aos árbitros, o fazer batota, as agressões entre os praticantes devem-se ao reforço do conceito de que a vitoria é a única coisa que interessa.

Mas, será que é possivel praticar desporto e entrar em competições, revelando indiferença face ao resultado final, como se ele não tivesse qualquer valor? Não, não faz sentido participar numa competição desportiva se essa presença não estiver desligada da tentativa de vencer.

$O$ respeito pelo regulamento das modalidades é o primeiro factor que condiciona as tentativas dos participantes no sentido de serem eles os vencedores, definindo o significado de "ganhar". Outra limitação aos esforços dos praticantes, no sentido de vencerem as competições em que participam, tem sido a noção de desportivismo ou de ética desportiva. Ideias como as do respeito pelo adversário, a recusa de situações injustas de vantagem, a modéstia no momento da vitória e o facto de se saber perder têm servido, de diferentes maneiras, para se definir aquilo que é melhor e mais civilizado, os limites razoáveis dos esforços para vencer, procurando manter as emoções, associadas às vitorias e às derrotas, sempre sob controlo, mesmo quando elas são muito intensas.

Em relação a uma ética no desporto é necessário o empenho de todas as pessoas envolvidas com este fenómeno, através de acções como: a defesa de uma prática desportiva pautada por valores morais, éticos e deontológicos; que sejam adoptados dentro do ponto de vista de uma ética da responsabilidade, situando-nos no interior do desporto para criticá-lo; e, finalmente, criticar o universo do desporto moderno em nome de promessas que ele faz e não cumpre ${ }^{12}$.

Mas afinal, como podemos definir o conceito de ética desportiva? É preciso ter em consideração que a "sua tarefa é, pois, a de reflectir sobre o desporto como um lugar de moralidade no contexto da vida sócio-cultural"4.

Mais especificamente, por ética desportiva, entende-se o conjunto de valores morais existentes na prática desportiva, condenando a violência, a corrupção, a dopagem e qualquer forma de discriminação social ${ }^{14}$.

É através da ética que se podem traçar, pelo menos de uma maneira teórica, os limites do custo do sucesso, definindo um conjunto de critérios que possibilitem saber qual o significado de uma vitória a qualquer preço ${ }^{15}$.

Como já foi referido existem várias interpretações acerca do conceito de ética. A ética associada ao desporto adquire um novo termo Espírito Desportivo - Fair Play.

Os fairs eram os mercados da Idade Média onde se cultivava a honestidade, lealdade, cavalheirismo, justiça e seriedade ${ }^{4}$. Este conceito, que está associado ao espírito desportivo, foi agregado no desporto no final do século XIX, através de Pierre de Coubertin "O esforço é a alegria suprema; o sucesso não é um objectivo, mas apenas um meio de visar mais alto"15.
O fair play significa muito mais do que o simples respeitar das regras; mas cobre as noções de amizade, de respeito pelo outro, e de espírito desportivo, um modo de pensar, e não simplesmente um comportamento. 0 termo Espírito Desportivo é definido na literatura especializada como um código de atitudes; respeito pelas normas prescritas derivadas de um código de Ética; um mero comportamento moral assumido no meio desportivo ${ }^{16}$.

Tal como refere o Comité Internacional para o Fair Play ${ }^{17}$ o espírito desportivo não é uma noção que diz apenas respeito ao desporto, mas o próprio princípio de toda a coexistência e de toda a cooperação entre os Homens. Todo o Homem deveria ter a possibilidade de fazer desporto no quadro do espírito desportivo. Todas as pessoas, seja qual for a sua raça, origem, sexo, idade e capacidades - do profissional ao diminuído físico - deveriam poder praticar desporto segundo as suas necessidades, cultura e capacidades físicas.

Para se familiarizarem com os comportamentos conformes ao espírito desportivo, os Homens devem poder fazer as suas provas em situações que lhes permitam cooperar entre si.

A prática do desporto, num quadro que respeite os princípios da ética desportiva, é, pois, uma meta em si possivel, embora bastante difícil, constituindo igualmente uma forma de procurar, com a sua força e com maior abertura revelada pelo praticante desportivo, criar o respeito por valores semelhantes, num cenário de aplicação muito mais amplo. A realidade mostra que o desporto, sob acção de diversos factores, afasta-se, muitas vezes, da confirmação das suas potencialidades e do desempenho do seu papel formativo e educativo. Tem-se verificado um acréscimo significativo de 
situações conflituosas e a competição é disputada à margem das regras e dos regulamentos, decorrendo num envolvimento inadequado, sobretudo para crianças e jovens. Assim, é importante adoptar, da ética desportiva, uma visão tão realista quanto possivel, estabelecendo as suas características a partir dos factos concretos e da dinâmica própria da actividade desportiva e dos diferentes protagonistas, em vez de ter a pretensão de submeter a realidade a uma ideia, conceito ou definição formulados à margem daquela.

A promoção e o desenvolvimento da ética desportiva deve-se integrar numa perspectiva de desenvolvimento cultural, educativo e cívico.

0 desporto deve proporcionar 0 prazer e o sucesso, mas não a qualquer preço. Os atletas devem aprender, nas suas actividades desportivas, a não ultrapassar certos limites, a não enganar o concorrente, fazer batota ou mesmo provocar danos corporais. Contudo, isto só pode ser fruto de uma educação sistemática a favor do espírito desportivo. Os monitores, treinadores e animadores deveriam ser preparados para esta tarefa, de modo a não ficarem prisioneiros da rotina. Além disso, as federações desportivas deveriam publicar directivas relativas aos desportos de tempos livres e sugerir actividades desportivas adequadas.

Para reforçar o valor do acto desportivo e dos seus resultados, é necessário que a luta pela afirmação de superioridade, pela vitória, decorra dentro dos limites estabelecidos pelas regras, elas próprias em constante evolução no sentido de garantirem, aos opositores, igualdade de circunstâncias e de contrariar situações de fraude e de violência.
Uma consequência importante de um código de comportamento como o da ética desportiva é a possibilidade de, em certa medida, se poder distinguir o valor da vitória em si mesma. Ganhar tanto pode ser uma honra como uma vergonha, em termos de código de comportamento que determinou esse facto.

É necessário compreender o Espírito Desportivo - Fair Play, não como um processo mágico ou ingénuo, mas sim como um fenómeno directamente dependente do contexto social, das acções responsáveis dos dirigentes da sociedade e do desporto, como também um componente estreitamente relacionado com o contexto educacional, no qual a educação moral, educação desportiva e Espírito Desportivo - Fair Play podem ser incorporados por crianças e jovens, como comportamentos importantes no exercício da cidadania plena numa sociedade democrática $^{18}$.

Em suma, Ética Desportiva surge como uma estrutura moral que define alguns limites para o comportamento dos desportistas, de forma a preservar um sistema desportivo civilizado. É possível competir respeitando o adversário, reconhecendo o seu valor e competência, vendo-o como um oponente indispensável, sem o qual não existe competição. As regras da Ética Desportiva exigem que, além de respeitar o adversário, se saiba reconhecer o mérito do vencedor, guardando para si os sentimentos de tristeza e desapontamento.

\section{2. Ética no Desporto para Crianças e Jovens}

"No desporto dos jovens, os verdadeiros vencedores não são necessariamente os atletas medalhados" (Kemp, 1991)
Num mundo de carácter desportivo, e social, onde se assiste cada vez mais à luta pela vitória pessoal, custe o que custar e doa a quem doer, colocando muitas vezes em risco a saúde física e psíquica de crianças e jovens, tudo isto para se alcançar o êxito pessoal, colocando em segundo plano os interesses pessoais dos jovens como o seu desenvolvimento enquanto ser humano que pratica desporto.

Vamos deixar as crianças serem crianças, não podemos estar constantemente a bombardeá-las com normas e valores que nada têm a ver com o seu mundo, numa tentativa de corrompê-las pelo quotidiano frustrado dos adultos ${ }^{15}$.

Apesar de muitos alertas para o facto de a criança não ser um adulto em miniatura ${ }^{19,20,21}$ parece existir uma tendência a esquecê-lo, ou será que é por conveniência que o fazemos?

Numa sociedade que valoriza acima de tudo o resultado e não se importa com os meios para alcançar os fins, esta situação é tarefa fácil. Como questiona Personne ${ }^{22}$ "Será que uma medalha vale a saúde de uma criança?" -, a resposta a esta questão é a Ética.

Esta visão aqui traçada é real, e não toma como referência só o desporto de alto rendimento, mas sim todo em geral. Apesar de todo o conhecimento que chega até nós, parece que ainda temos uma certa dificuldade em ultrapassar esta questão. Não se poderá dizer que a culpa desta situação é só do treinador, mas sim de todos os intervenientes neste processo.

Martens $^{23}$ afirma que não é o confronto, a competição ou o tipo de Desporto praticado que determina automaticamente o valor das actividades desportivas para as criancas e jovens; é antes do mais a natureza das experiências vividas 
nessas actividades. São principalmente as interacções com os pais, os treinadores, os professores, os dirigentes, os árbitros, os companheiros de equipa e a assistência, que vão determinar se a prática desportiva ajuda ou não as crianças e os jovens a adquirirem uma sã convivência social e desportiva.

Não podemos deixar de dizer que a questão ética tem uma importância redobrada no contexto do desporto para crianças e jovens. Esta não passa apenas pelo reconhecimento e desenvolvimento de atitudes que respeitem a própria natureza da criança no contexto do referido conflito desportivo lo respeito por si própria e pelo adversário, a valorização do seu empenho e esforço, o modo de lidar com o sucesso e insucesso, etc.J. 0 mais importante é a intervenção do adulto nesse contexto, onde a maioria das vezes usa e abusa sem ter atenção as consequências desses actos. Todo o processo de treino/competição deve ser repensado, através de uma nova abordagem ética, onde o resultado não seja objectivo exclusivo, traçando limites para que a vitoria não seja alcançada à custa da violentação do ser: a criança ${ }^{21}$. 0 princípio fundamental da prática desportiva de crianças e jovens, deve sempre tomar em consideração e orientar-se pelo interesse do jovem que a pratica, tendo todos os agentes de socialização e em especial, os professores de Educação Física e treinadores, a responsabilidade e obrigatoriedade de pro-mover e zelar pelo respeito dos valores desportivos, durante a sua intervenção ${ }^{24}$.

Como diz Proença $a^{20}$ "partamos para a redescoberta da alegria e do prazer, subordinando as metodologias a princípios éticos e contribuindo para uma vida mais feliz. Porque para outra coisa não entendemos o treino de Jovens".

\section{CONCLUSÕES}

"O espírito desportivo valoriza a inteligência, o corpo e o espírito do homem, que se distinguem pelos seguintes valores: ética, fair play e honestidade, saúde, excelência no rendimento, carácter e educação, diversão e alegria, trabalho de equipa, dedicação e respeito pelas regras e leis, respeito por si

e pelos outros participantes, coragem, comunidade e solidariedade"

[Comentário numa reunião do programa mundial Anti Doping]

É irrefutável o facto de que o Desporto transmite uma série de valores, quer sejam próprios da sociedade em que está inserido ou por outro lado, pré-estabelecidos pelas sociedades antecedentes ${ }^{25}$.

Nas últimas décadas, tem-se tornado numa componente importante da sociedade moderna, dado que os jovens dispõem de mais tempo livre e o Desporto desempenha um papel relevante nos domínios da educação, saúde, lazer, etc. ${ }^{16}$

Assiste-se cada vez mais que o comportamento dos jovens, no e perante o Desporto, tem vindo a sofrer alterações. Alguns comportamentos que têm vindo a ser mais frequentes são: fazer batota, praticar agressões, adoptar comportamentos violentos e faltar ao respeito a adversários e árbitros. Embora as ocorrências mais frequentes e visíveis sejam observáveis no Desporto profissional, já se começa a encontrar cada vez mais esses "maus" comportamentos no Desporto jovem, o que tem provocado um aumento de estudos por parte de investigadores nesta área ${ }^{26}$.

Os problemas e interrogações relativas ao respeito pelo fair play e espírito desportivo e pela ética constituem uma importante área de preocupação para todos aqueles que procuram intervir com sentido crítico na evolução das práticas desportivas e dos respectivos processos de ensino-aprendizagem ${ }^{27}$. O Espírito Desportivo é um dos temas fulcrais do futuro do Desporto, uma vez que exige uma atitude moral fundamental. Segundo Daume $^{28}$ substituiu a componente ética do antigo conceito de "amadorismo". Se a violência é o sinal do nosso tempo, o Espírito Desportivo representa a necessidade e talvez mesmo a solução da sua superação. Num tempo caracterizado pelo imediatismo, pelo individualismo e competição exacerbada, pela vitória e bens materiais como indicadores de sucesso, compete ao ensino universitário, particularmente na área de formação de professores e treinadores, dar um contributo sério para uma formação superior de verdadeira qualidade, uma formação integral científica, técnica e pedagógica, mas também cultural e humanista em que, além da apropriação do saber, aprendamos a ser ${ }^{29}$. A escola e a sociedade em que queremos viver não podem prescindir da impulsionadora e exigente participação de alunos, funcionários e professores que sejam criadores e transmissores de conhecimentos, mas também incentivadores de cultura e promotores de valores. Assim, a escola desempenha um papel crucial na formação global do indivíduo e na inserção deste, de forma crítica e consciente, na sociedade.

Não faltam motivos para que todos, no âmbito da nossa actividade profissional e fundamentalmente através do exemplo, contribuamos para a existência de uma ética de responsabilidade, liberdade e solidariedade que nos dignifique e honre a condição humana ${ }^{29}$. 
Por isto tudo defendemos que os valores da ética desportiva, como componente particular da ética por que se deve pautar o relacionamento humano, deverão fazer parte das preocupacõos dos adultos que dirigem e orientam a prática desportiva juvenil, condicionando, por esta via, a qualidade da experiência vivida pelos jovens praticantes e, com ela, a dimensão dos efeitos e a profundidade das marcas deixadas em cada um deles ${ }^{30}$.

\section{CORRESPONDÊNCIA}

Carla Marisa Maia Moreira

Gui Duarte Meira Pestana

Morada: Rua Sobregião, 219

4780-551 Santo Tirso

E-mail: carla_m_moreira@sapo.pt

Telm. 936662774

\section{REFERÊNCIAS}

1. Puga A (2002). Ética e Contemporaneidade: o desporto profissional e a inserção das sociedades desportivas e do clube-empresa. Conferência proferida no 9ㅇ Congresso de Educação Física e Ciências do Desporto dos Países de Língua Portuguesa, São Luís/MA.

2. Gonçalves C (2003). A Educação para os Valores nas actividades físicas escolares. Notícias do Espírito Desportivo, n. ํ 21. Oeiras.

3. Constantino JM (1998). Editorial. Notícias do Espírito Despor-

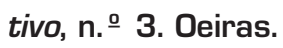

4. Bento JO (1998). Desporto e Humanismo: O Campo do Possível. Ed. Uerj: Rio de Janeiro.
5. Paddick RJ (1991). A ética desportiva e a luta pela vitória. Treino Desportivo, 21 (II), 8-17.

6. Carreiro da Costa F (2001). 0 desporto, actividade cultural e educativa. Notícias do Espírito Desportivo, n. ํ 15. Oeiras.

7. Cordovil J (2004). Remar contra a maré. Notícias do Espírito Desportivo, n. ํ 26. Oeiras.

8. Gonçalves C (1991). A prática desportiva das crianças e dos jovens: Contributos para o seu alcance educativo e formativo. In J. Bento \& A. Marques (Eds.), As ciências do Desporto e a prática desportiva: Desporto na escola; Desporto na reeducação e reabilitação - Actas, pp. 521-532. Porto: FCDEF-UP.

9. Cruz S (2002). Em torno da ética e do fair-play. Notícias do Espírito Desportivo. (On-Line): 16(5), 5. (OnLine): http://www.cm-oeiras.pt.

10. Viana M [s.d.). Ética geral e profissional. Livraria Figueirinhas. Porto.

11. Garcia R (1997). Contributo para a legislação de um discurso ecológico no desporto: a cultura. In Revista Horizonte, vol. XIII, n. ำ 75, pp. 15-23.

12. Bento JO (1990). À procura de referências para uma ética do Desporto. In J. Bento \& A. Marques (Eds.), Desporto, Ética e Sociedade - Actas [pp. 23-39). Porto: FCDEF-UP.

13. Santos R, Roazzi A (1997). O Espírito Esportivo entre portadores de deficiência e universitários da cidade do Recife, Pernambuco, Brasil. In Revista Corporis. Ano II, n. ㅇ 2, pp. 29-37.

14. Meirim JM (1995). Dicionário Jurídico do Desporto. Lisboa, Edicões Record. Minnesota.

15. Cid L (2002). Reflexão sobre Ética no desporto para crianças e jovens. In Revista Horizonte. Vol. XVIII, n. 104, pp. 36-39.
16. Gonçalves C (1990). Espírito Desportivo: Questão de ética, questão de educação. In J. Bento \& A. Marques [Eds.], Desporto, Ética e Sociedade - Actas, pp. 87-105. Porto: FCDEF-UP.

17. Comité Internacional para o Fair-Play. (1995). 0 Espírito Desportivo no Desporto para Todos, de Tempos Livres e Manutenção In: 0 Espírito Desportivo nas Práticas Desportivas. [On-Line]: http://www.cm-oeiras.pt/ /Desporto/folheto_5.htm\#Início

18. Santos R (2002). Para centrar a intervenção nas questões do Espírito Esportivo - Fair Play. IX Congresso de Educação Física dos Países de Língua Portuguesa. São Luís, Maranhão.

19. Candeias J (1998); Crianças e formação desportiva. In Treino Desportivo, III série, Edição Especial, pp. 3-10.

20. Proença J (1998). A identidade do treino de jovens: Da ética à metodologia. In Treino Desportivo. II série, Edição Especial, pp. 11-14. 21. Garcia e Rolim (1995). Reflexão sobre Ética no desporto para crianças e jovens. In Horizonte Revista. vol. XI, n. ํ 66, pp. 221-227. 22. Personne J (1987). Nenhuma medalha vale a saúde de uma criança. Livros Horizonte. Lisboa.

23. Martens R (1978). Joy and sadness in children's sports. Champaign: Human Kinetics.

24. Fernandes H. (2003). Uma perspectiva multidimensional dos valores morais no contexto desportivo. (On-Line):

http://www.psicodeporte.com

25. Rijo AG (2001). Deporte y moral: Los valores educativos del deporte escolar. EFDeportes [On-Line):31(6). (On-Line):

http://www.efdeportes.com 
26. Bredemeier B (1984). Sport, gender and moral growth. In J. Silva \& R. Weinberg (Eds.). Psychological foundations of sport and exercise (pp. 400-414). Champaign: Human Kinetics.

27. Curado J (2003). Fair play. problemas da realidade portuguesa urgência de intervenções preventivas. Notícias do Espírito Desportista, n. ำ 22. Oeiras.

28. Daume W (2000). O Espírito Desportivo nas práticas desportivas. (On-Line):

http://www.cm-oeiras.pt

29. Proença J (2001). A ética na formação universitária de profissionais de educação física e desporto. Notícias do Espírito Despor-

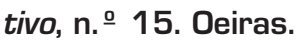

30. Adelino J (1998). A Importância da Ética Desportiva na Prática Desportiva Juvenil. Notícias do Espírito Desportivo, n. $\cong$ 1. Oeiras. 